\title{
Geografia, Arquitetura e Arte: edificações em madeira na paisagem iratiense retratada por Primo Araújo
}

\author{
Geografía, Arquitectura y Arte: edificaciones en madera en el \\ paisage iratiense retratada por Primo Araújo
}

\section{Geography, Architecture and Art: Wooden Buildings in the Irati Landscape depicted by Primo Araújo}

\author{
Andressa Maria Woytowicz Ferrari \\ andressa_ferrari@hotmail.com \\ PPG, Universidade Estadual de Ponta Grossa, UEPG, PR \\ Cicilian Luiza Lowen-Sahr \\ cicilian@uol.com.br \\ PPG, Universidade Estadual de Ponta Grossa, UEPG, PR
}

\begin{abstract}
Resumo: Ao longo dos anos, as edificações em madeira no município paranaense de Irati vêm sendo substituídas, perdendo-se assim parte da história e do patrimônio cultural arquitetônico local. O objetivo deste estudo é analisar tal dinâmica na paisagem recorrendose a obra do pintor-escultor local Primo Araújo. Relacionando Geografia, Arquitetura e Arte interpretam-se os elementos visuais que compõem as paisagens retratadas, buscando-se as interfaces existentes entre essas áreas. A triangulação das informações apresentadas na obra do artista se dá através de bibliografia e entrevistas. Conclui-se que entre as diferentes interpretações que uma obra de arte pode sugerir, destaca-se a de desvendar paisagens esquecidas do passado.
\end{abstract}

Palavras-chave: Cultura, História, Desenho Artístico, Passado.

Resumen: A lo largo de los años, las edificaciones en madera en el municipio paranaense de Irati vienen siendo sustituidas, perdiéndose así parte de la historia y del patrimonio cultural arquitectónico local. El objetivo de este estudio es analizar tal dinámica en el paisaje recurriendo a la obra del pintor-escultor local Primo Araújo. Relacionando Geografía, Arquitectura y Arte se interpretan los elementos visuales que componen los paisajes retratados, buscando las interfaces existentes entre esas áreas. La triangulación de las informaciones presentadas en la obra del artista se da a través de bibliografía y entrevistas. Se concluye que entre las diferentes interpretaciones que una obra de arte puede sugerir, se destaca la de desentrañar paisajes olvidados del pasado.

Palabras-clave: Cultura, Historia, Diseño Artístico, Pasado.

Abstract: Over the years, the wooden buildings in the municipality of Irati have been replaced, causing a partial loss of local history and architectural heritage. The main objective of this study is to analyze the landscape dynamics through the work of the local sculptor-painter Primo Araújo. Relating Geography, Architecture and Art, the interpretation of the visual elements that are composing the portrayed landscape aims at revealing the relations between these areas. The triangulation of the elements in 
the artist's oeuvre is based on bibliography and interviews. The research highlights that specific interpretations of artwork can induce the reconstruction of forgotten landscapes of the past.

Key words: Culture, History, Artistic Drawing, Past.

\section{INTRODUÇÃO}

A Arte, Arquitetura e Geografia apresentam inter-relações e interconexões que permitem a articulação de conhecimentos das ciências naturais e humanas. A análise de elementos edificados na paisagem proporciona o reconhecimento de interfaces uma vez que permite identificar tradições técnicas herdadas de diferentes culturas e também o poder simbólico das mesmas através dos anos, auxiliando na reconstrução da história e da paisagem local. Neste artigo busca-se avaliar as edificações de madeira como elementos da paisagem do município paranaense de Irati. $O$ objetivo do estudo é verificar, através destas edificações, a dinâmica das paisagens locais a partir do início do século XX tomando por base uma das obras do artista local Primo Araújo. A obra selecionada é um desenho executado pelo artista em lápis de cor sobre papel Kraft. O desenho retrata um eixo comercial importante para a cidade na atualidade.

O município de Irati, localizado a $156 \mathrm{~km}$ da capital Curitiba, situa-se na região Centro Sul do estado do Paraná, que se caracteriza por paisagens de Campos Naturais e Floresta com Araucária permeadas por antigas edificações em madeira. Inicialmente ocupadas pelos índios Caingangues e caboclos, as terras dessa região foram palco do movimento de tropeiros e colonizadas por povos europeus de diferentes etnias. De acordo com Kiewiet e Kiewiet (2011), os primeiros colonizadores, holandeses e alemães, chegaram em 1908 à colônia de Gonçalves Júnior, localizada a $20 \mathrm{~km}$ de sua sede urbana.

Irati foi fundada ao longo da linha sul da Estrada de Ferro São Paulo/Rio Grande e teve seu ápice econômico entre 1899, com a inauguração da ferrovia, e 1940, época do "auge da utilização da ferrovia como transporte de passageiros e de cargas, fato que é muito lembrado pela comunidade local, inclusive por aqueles que não vivenciaram esse momento da história" (DEMCZUK, 2011, p.11). A ferrovia trouxe consigo o desenvolvimento econômico e possibilitou o crescimento da cidade através da atração de pessoas de outras localidades.

Durante o ciclo econômico da madeira no Paraná, na primeira metade do século XX, esta foi uma das principais matérias primas extraídas da região. O início da exploração madeireira na região ocorreu por volta de 1871, com o estabelecimento da Companhia Florestal Paranaense. Entretanto, somente com a abertura da estrada da Graciosa em 1873, ligando Curitiba à Antonina, com a construção da Estrada de Ferro Paranaguá-Curitiba em 1885 e do ramal Morretes-Antonina em 1891 foi que a exploração da Araucária se tornou 
importante atividade econômica para o estado (CARVALHO; MEDRADO; HOEFLICH, 2003).

Conforme Kiewiet e Kiewiet (2011, p.21) apenas " no ano de 1919, foram embarcadas em Irati aproximadamente 1.500 vagões de madeiras serradas, de pinho e imbuia". As matas densas de Araucárias eram exploradas com a finalidade de exportação da matéria prima, fator alavancado com a Primeira Guerra Mundial. A partir de então as serrarias foram se multiplicando e as reservas de pinheiros diminuíram rapidamente, fazendo com que a madeira superasse a importância econômica da erva-mate, que preponderava no Paraná até então.

A expansão do transporte rodoviário após 1930 também facilitou a exploração por parte da indústria madeireira, que não dependia mais apenas das ferrovias para escoar sua produção. A crise da produção de erva-mate fez com que o ciclo econômico do pinheiro ganhasse força, havendo a abertura de muitas indústrias regionais ligadas à madeira (CARVALHO; MEDRADO; HOEFLICH, 2003).

A abundância da matéria prima florestal em Irati e as técnicas construtivas trazidas pelos imigrantes se refletiram na tipologia das primeiras residências e demais edificações do município. Na fase inicial se tratava de construções de baixa complexidade. Com o passar do tempo, entretanto, assistiu-se a uma diferenciação socioeconômica marcada pelo grau de complexibilização das construções, ou seja, por edificações de mais de um pavimento, com maior área construída e também pelo provimento destas com adornos.

A maioria das edificações em madeira de Irati, todavia, foi se deteriorando e/ou desaparecendo ao longo do tempo, o que se configurou em dano irreversível em termos de patrimônio arquitetônico. Identificou-se a perda até mesmo de exemplares relevantes do contexto histórico da cidade, tais como a primeira estação de trem - Estação Iraty, o primeiro cinema - Cine Theatro Central, a antiga Prefeitura Municipal e a Padaria Iraty. Daí a relevância do presente estudo, que valoriza a manutenção da memória e do patrimônio cultural como legado da formação sociocultural local e regional.

A paisagem iratiense do início do século $X X$, marcada pela presença de edificações em madeira de caráter residencial, religioso, comercial e industrial, foi retratada tanto em fotos antigas como em obras de arte. Entre estas imagens do passado, destacam-se as realizadas por Primo Araújo (1902-1998), renomado artista local. A produção do artista é bastante vasta e se caracteriza por diferentes estilos que variam entre desenhos, pinturas e esculturas. Elementos reminiscentes desta paisagem retratada pelo artista podem ainda hoje serem pontualmente observados no município.

A temática central desta investigação são as edificações em madeira enquanto elementos da paisagem do município paranaense de Irati. A partir de uma das obras de Primo Araújo, busca-se, através da análise dos elementos empíricos nela presentes, trazer uma contribuição teórica para reflexões que, como esta, expressem a interface entre a Geografia, Arquitetura e Arte. 


\section{A PAISAGEM COMO INTERFACE ENTRE A GEOGRAFIA, ARQUITETURA E ARTE: REFLEXÕES TEÓRICAS}

O conceito de paisagem referente a uma pesquisa sócio espacial, como defende Souza (2013, p.44), está ligado ao “espaço abarcado pela visão de um observador”, o que também inclui a "representação visual e pictórica de um determinado espaço". Assim, o método descritivo da paisagem, utilizado neste estudo, se refere ao conceito de paisagem da Geografia relacionado à sua dimensão pictórica, visível nas Artes Plásticas e na História da Arte.

Neste sentido, a paisagem não é vista apenas como um modelo científico e acabado, mas aberta a diversas possibilidades de interpretações de acordo com o observador. Assim, traz em si mesmo aspectos psicológicos, emocionais, culturais, históricos e sociais que interferem na leitura que se faz da paisagem.

Como afirma Souza (2013, p. 46):

A ideia da paisagem nos remete, inicialmente, não à ciência, mas sim à pintura, mais especificamente à pintura da Renascença na Itália e, principalmente em Flandres (...). Eis, portanto, uma das muitas situações em que fica evidente que a ciência não basta a si mesma, devendo, humildemente, deixar-se fecundar por outras formas de saber, como o "saber local" (local knowledge) dos não especialistas, as artes e a Filosofia. (grifo dos autores).

Portanto, neste estudo a Geografia e Arte se aproximam e se complementam. Contemplar a paisagem e encontrar seus significados vai além de identificar os objetos que podem ser percebidos visualmente na mesma. Ou seja, a totalidade da paisagem não se restringe ao seu conteúdo, há uma série de subjetivismos próprios da observação, além é claro dos subjetivismos utilizados pelo sujeito que já transformou a paisagem real em uma imagem, uma obra de arte que vai além do que um dia foi captado pelo olhar do artista.

Andreotti (2013) menciona este aspecto quando reflete sobre as colocações realizadas por Lehmann ${ }^{1}$, que sugerem que a paisagem ao mesmo tempo em que parece objetiva, é um "quadro de aparência visual integrada", o que significa não dar ênfase ao aspecto objetivo da paisagem, mas relacioná-la ao caráter psicológico que pode representar. "A integração a que se refere Lehmann tem como fatores visíveis (...) a valorização estética, os elementos culturais, a temporalidade, e, como fator invisível, o aporte psicológico." (ANDREOTTI, 2013, p. 30).

Através da observação de uma obra de arte, feita a partir das impressões do artista iratiense Primo Araújo, reproduzindo determinada paisagem em determinado tempo, este estudo sugere interpretar não apenas o que está retratado na paisagem, transformada em desenho. Vai-se além, seguindo-se o sugerido por Souza (2013), ou seja, interpreta-se também aquilo que se oculta, ou seja, as relações sociais, as relações de trabalho, os fatos históricos, entre outros.

1 LEHMANN, H. Formen Landschafticher Raumerfahrung im Spiegel der bildenden Kunst. Mitt d. Fränkischen Georg., Bd. 13/14, 1966/67, s. 1-24. 
A Arte contribui para esta interpretação, pois como forma de expressão representa uma linguagem que comunica algo a seus observadores. As artes, e em especial neste estudo as artes plásticas, apresentam uma importância fundamental para a sociedade. É através da Arte que se permite registrar aspectos intrínsecos a determinada sociedade, a determinado discurso ou intenção, bem como, a determinado ponto de vista. Assim, estudar uma obra de arte, ou um conjunto de obras, pode consistir numa "verdadeira pesquisa histórica, que se propõe a interpretação dos significados e valores" (ARGAN, 2014, p. 15).

Neste sentido, parte-se do pressuposto de que a Arte, ainda segundo Argan (2014, p.16), é uma fonte que pode ser estudada historicamente por ser uma das "linhas mestras de desenvolvimento da civilização". Portanto, é a partir deste instrumento, um desenho artístico, que se estrutura a análise presente neste artigo.

O apoio de aparatos visuais é essencial ao trabalho do geógrafo e há extensa bibliografia a respeito da importância do uso de imagens nas pesquisas geográficas. De acordo com Gomes e Ribeiro (2013), as imagens são instrumentos de percepção e compreensão do mundo, configurando mais do que exemplos ou ilustrações. Estas imagens abrangem diferentes instrumentos: mapas, fotografias, produções audiovisuais, desenhos, pinturas, obras de arte em geral, monumentos, entre muitos outros.

A interface entre Geografia e Arte é discutida por muitos autores (NOVAES, 2013; GOMES; RIBEIRO, 2013; MARQUEZ, 2006; FERREIRA, 2017). Igualmente vários pesquisadores se utilizam da análise de obras de arte para desenvolver estudos geográficos, como Ferreira (2017) sobre as pinturas de Cândido Portinari na compreensão da evolução e adensamento das favelas no Rio de Janeiro; e o trabalho sobre os desenhos de Percy Lau, feitos para a Revista Brasileira de Geografia na série 'Tipos e Aspectos do Brasil', para o entendimento de representações nacionais baseadas em regionalismos (ANGOTTI-SALGUEIRO, 2005). Ambos abordam as representações a partir da visão de mundo estabelecida pelos autores e de como estas colaboram para os estudos geográficos.

Assim, o foco principal deste trabalho é fazer a aproximação entre estes dois campos do conhecimento a partir da definição de algumas categorias de análise específicas no campo da Geografia e Arquitetura. Para tanto, como referência metodológica, este estudo se baseia na análise de conteúdo proposta por Bardin (1977).

A análise de conteúdo, conforme Silva e Fossá (2015), é uma técnica da Ciência da Comunicação que busca classificar os dados em temas ou categorias que auxiliem a compreensão do que está além dos discursos. Ela pode ser aplicada para a análise de documentos, textos, entrevistas, cartas, fotografias, vídeos, anúncios, filmes, entre outros. Como afirmam Silva e Fossá $(2015$, p.3):

A análise de conteúdo, atualmente, pode ser definida como um conjunto de instrumentos metodológicos, em constante aperfeiçoamento, que se presta a analisar diferentes fontes de conteúdos (verbais ou não-verbais). Quanto à interpretação, a análise de conteúdo transita entre dois polos: o rigor da objetividade e a fecundidade da subjetividade. 
Para Bardin (1977, p.31) “a análise de conteúdo é um conjunto de técnicas de análise de comunicações" que visa ir além da compreensão dos seus significados imediatos, ultrapassando incertezas de uma visão pessoal. A organização da análise de conteúdo para o autor se dá em três fases: 1. A pré-análise; 2. A exploração do material; e 3. O tratamento dos resultados, a inferência e a interpretação. Na primeira fase é realizada a escolha dos documentos que serão analisados, definidos os objetivos e hipóteses da análise e, por fim, elencados os indicadores que darão embasamento a interpretação final. Na segunda fase realizam-se operações de codificação e enumeração conforme o que foi previamente planejado na etapa anterior, esta fase consiste na análise propriamente dita. Por fim, na fase do tratamento dos resultados e interpretação, os resultados são validados e se tornam significativos.

Portanto, seguindo as fases descritas no parágrafo anterior, inicialmente fez-se a escolha do objeto a ser analisado, ou seja, a seleção do desenho de Primo Araújo que serviria a este estudo, definindo os objetivos da pesquisa e estabelecendo as categorias de informações a serem identificadas no desenho. Estas categorias compreendem a identificação e descrição: 1. Dos elementos contextuais; 2. Das edificações em madeira; e, 3. Utilizando-se de fotografias atuais, dos elementos remanescentes. Posteriormente aplicou-se a análise seguindo as categorias propostas, enumerando-se todas as informações pertinentes às mesmas. O tratamento dos resultados e a interpretação consistem na consolidação das informações anteriormente elencadas, validando as mesmas através da confrontação destes dados com fontes bibliográficas e visitas in loco.

Como complemento, além da Geografia e da Arte, insere-se nesta interpretação ainda conceitos relacionados à Arquitetura. Como o desenho selecionado para este estudo está isento de figuras humanas, é através das características arquitetônicas que se buscará a interpretação do espaço construído contido na representação da paisagem. O foco são as edificações em madeira representadas e que retratam a cidade nas primeiras décadas do século XX.

A Arquitetura auxilia no entendimento da cultura e história, pois as construções representam o palco da vida cotidiana e constituem as marcas do homem na paisagem. Como afirma Zevi (1996, p.26):

Cada edifício caracteriza-se por uma pluralidade de valores: econômicos, sociais, técnicos, funcionais, artísticos, espaciais e decorativos, e cada um tem a liberdade de escrever histórias econômicas da arquitetura, histórias sociais, técnicas e volumétricas (...).

O rigor científico da análise da paisagem, portanto, se dá através da descrição objetiva dos elementos representados no desenho selecionado, já os aspectos psicológico e emocional estão relacionados a três enfoques distintos: inicialmente o do artista que buscou através do desenho congelar a paisagem de determinado período histórico de Irati; as impressões de um de seus filhos sobre a obra e sua própria experiência de vida nesta localidade ao longo dos anos; e, por último, a percepção das pesquisadoras a partir de seus conhecimentos relacionados à Arquitetura e também ao Urbanismo. Cada um dos 
sujeitos mencionados no parágrafo anterior, a partir da sua própria consciência sobre os elementos, traz sua intenção em elucidar e decodificar a paisagem.

Como instrumento para a interpretação da imagem e consequente análise das relações sócio espaciais nela representadas, são utilizados subsídios da Geografia, Arquitetura e Arte. A contribuição da Geografia concerne à aplicação do conceito de paisagem através de uma postura integradora, totalizante, onde não apenas a descrição objetiva importa. A Arquitetura imprime valor à identificação dos elementos construídos como oportunizadores de relações sociais e culturais implícitas na imagem. A Arte articula-se aqui à Geografia e à Arquitetura por se tratar de uma análise a partir de uma representação subjetiva de Primo Araújo.

\section{BIOGRAFIA E OBRAS DE PRIMO ARAÚJO: UMA CONTEXTUALIZAÇÃO}

A vida e obra de Dario Araújo Primo, também conhecido como Primo Araújo, são apresentadas aqui a partir da perspectiva de seu filho, Zeca Araújo, e triangulação com outras fontes. As informações foram colhidas diretamente em duas entrevistas, em julho e em dezembro de 2016, bem como, indiretamente através de textos produzidos para órgãos de comunicação (ARAÚJO, 2010) e livros (FARAH; GUIL; PHILIPPI, 2008).

Zeca Araújo nasceu em 1940 e reside em Irati. É professor aposentado e realiza atividades, há mais de 10 anos, que promovem o conhecimento da história de Irati nas escolas do município. Ele também é responsável por um programa local na Rádio Najuá, denominado 'Irati de Todos Nós', que refere-se à história e cultura do município, e que vai ao ar aos sábados. Entre 1992 e 1994, já atuou como secretário de cultura na Prefeitura Municipal de Irati, e, seguindo os passos do pai, também é artista plástico.

Primo Araújo não era natural de Irati, mas do município paranaense de Piraí do Sul, tendo nascido em 25 de novembro de 1902. Era filho de Raymundo Araújo, ferroviário que em 1899 chefiou a Estação Iraty, e de Anália Veiga Araújo, telegrafista. Em 1919, aos 17 anos, mudou-se para Irati onde trabalhou até os 94 anos de idade, quando perdeu parte da visão em virtude de um glaucoma. Faleceu em 1998, aos 96 anos (ARAÚJO, 2010).

Segundo Araújo (2010), o artista iniciou seus estudos em uma escola alemã no município catarinense de Joinville e aos 15 anos foi estudar na Escola de Artífices em Curitiba, capital paranaense, escolhendo o ofício de alfaiate. Por seu destaque e habilidade nos desenhos de moldes e croquis de roupas foi convidado pelo diretor do educandário, em meados de 1917, a pintar os cenários do Theatro São Theodoro, que mais tarde tornou-se o afamado Teatro Guaíra.

Em 1924 alistou-se voluntariamente para lutar na Coluna Prestes ${ }^{2}$, durante o conflito nacional conhecido como "Revolução de 24". Foi para Curitiba junto com outros amigos iratienses para receber treinamentos de guerra no $15^{\circ}$ Batalhão. Próximo ao momento de ir para o conflito, em São Paulo, o governo federal alterou o comando deste Batalhão,

2 A Coluna Prestes foi um movimento político contrário ao governo da República Velha e às elites agrárias, entre 1925 e 1927. 
substituindo o oficial que era adepto à causa de Carlos Prestes por um comandante favorável a causa do governo. Assim, foi obrigado a lutar contra a Coluna Prestes (ARAÚJO, 2010).

Durante a perseguição militar aos revolucionários, iniciada em São Paulo e que se estendeu por todo o país, percorrendo florestas, serras, várzeas, campos e rios, Primo Araújo, por suas habilidades com o desenho, foi escolhido para representar em mapas "todas as fortificações, trincheiras, pontes e outros aparatos militares que os revoltosos deixavam para trás" (ARAÚJO, 2010, s.p.). Os desenhos ${ }^{3}$ foram utilizados pelo exército para que especialistas militares analisassem as técnicas de guerra empregadas pelos inimigos.

Apenas quando recebeu uma carta com a notícia da morte da mãe, Primo Araújo foi dispensado dos serviços militares, retornando à Irati. Dos cinco jovens de Irati que lutaram no combate, apenas ele e José Leite retornaram com vida (ARAÚJO, 2010). Após seu regresso, Primo Araújo casou-se com Iratyla. O casal teve cinco filhos: Mario, Teresa, Dario, Liana e José Maria, também conhecido como Zeca Araújo. Em 1941 morre sua esposa Iratyla e anos depois ele casa-se com Julieta Crissi (ARAÚJO, 2010).

Primo Araújo dominava diferentes métodos de representação gráfica: desenho a mão livre em lápis e papel, óleo sobre tela, aquarela, entre outros. Durante sua vida fez inúmeros registros do cotidiano de Irati e das paisagens locais. Aos finais de semana costumava sair junto com o amigo e também artista Rosinha, em busca dos cenários a serem retratados. Segundo Araújo (2010, s.p.), tratavam-se de "Cenas bizarras do dia a dia da sociedade, caricaturas de pessoas folclóricas, mudanças nas características da Vila eram seus principais enfoques".

Nas imagens produzidas por Primo Araújo aparecem os diferentes elementos da paisagem iratiense, dentre eles as inúmeras construções em madeira do município no início do século XX. Ele reproduzia a paisagem de outrora como a recordava, em desenhos realizados com lápis de cor sobre papel Kraft.

De acordo com Farah, Guil e Philippi (2008, p.46):

A memória extraordinária de Primo Araújo permitiu-lhe reproduzir imagens da cidade de Irati depois de passados mais de 50 anos. Desenhou com lápis de cor, na década de 1980, com uma precisão obsessiva, as principais quadras do centro da cidade no período 1915 - 1930. Em cada obra ele destaca nomes de ruas, residências e estabelecimentos públicos e comerciais.

Muitas das obras de Primo Araújo são propriedade de autoridades, personalidades e colecionadores. Zeca Araújo possui um amplo acervo das obras realizadas pelo pai, como desenhos realizados com lápis de cor sobre papel Kraft, xilogravuras e outras formas de arte. $\mathrm{O}$ acervo, além de quadros originais, possui várias fotografias digitais e reproduções impressas de obras do artista que foram doadas ou vendidas.

3 Estes desenhos, pela sua verossimilhança, reforçam a fidelidade do artista com uma representação realista em suas obras. Este fato colabora para a legitimação do uso de um de seus desenhos de Irati como objeto de análise neste artigo. 


\section{A ANÁlisE DE IMAGENS DA PAISAGEM COMO MÉTODO}

Estabelece-se a paisagem representada em imagens como categoria analítica para a presente investigação, tomando-a também como alicerce para as etapas de coleta e apreciação dos dados. Para tanto, é considerada a experiência humana da paisagem de acordo com as dimensões descritas por Berque (2004) e as relações entre elas: a) paisagem-marca: elementos físicos da paisagem e seus aspectos descritivos, tendo como foco central as edificações em madeira; b) paisagem-matriz: verificação de elementos subjetivos, significações, através da análise das experiências e consciências que estes revelam.

Corrêa (2011, p. 16), analisando diferentes obras de Cosgrove ${ }^{4}$, argumenta que:

As imagens são textos a serem decodificados e não formas que transmitem mensagens direta e imediatamente apreensíveis. Todavia, ao mesmo tempo, as imagens são construídas pelo geógrafo [poderíamos também dizer pelo artista], que, a partir de sua visão de mundo, para a qual a imaginação desempenha papel crucial, constrói representações sobre um dado aspecto da realidade.

A interpretação de imagens possibilita diferentes percepções, entre elas a identificação de formas de organização sócio espaciais. Tal perspectiva, de acordo com Colasante e Calvente (2012), é pertinente aos estudos geográficos.

Assim, inicialmente foram inventariadas na coleção de quadros e desenhos de Primo Araújo sobre Irati, aquelas obras que retratavam edificações em madeira. Selecionadas as imagens, escolheu-se uma que caracterizasse a cidade no início do século XX, período em que as construções eram apenas de madeira. Foram então realizadas entrevistas filmadas com o filho do artista, Zeca Araújo.

Desta forma, buscando apresentar uma análise diferenciada, foi selecionado para a análise, dentre o vasto acervo de obras do artista, um desenho executado em lápis de cor sobre papel Kraft que retrata a paisagem do conjunto arquitetônico de um eixo da cidade de Irati nos seus primórdios, a hoje denominada Rua Munhoz da Rocha (Fig. 1). É relevante ressaltar que o desenho foi elaborado na década de 1980 através das lembranças pessoais do artista de uma paisagem pertencente às primeiras décadas do século XX - período aproximado entre 1915 e 1930.

4 As principais obras do geógrafo britânico Dennis Cosgrove encontram-se listadas em Corrêa (2011, p. 17-19). 
Figura 1: Atual Rua Munhoz da Rocha - paisagem de Irati no início do século XX retratada na década de 1980 pelo artista Primo Araújo.

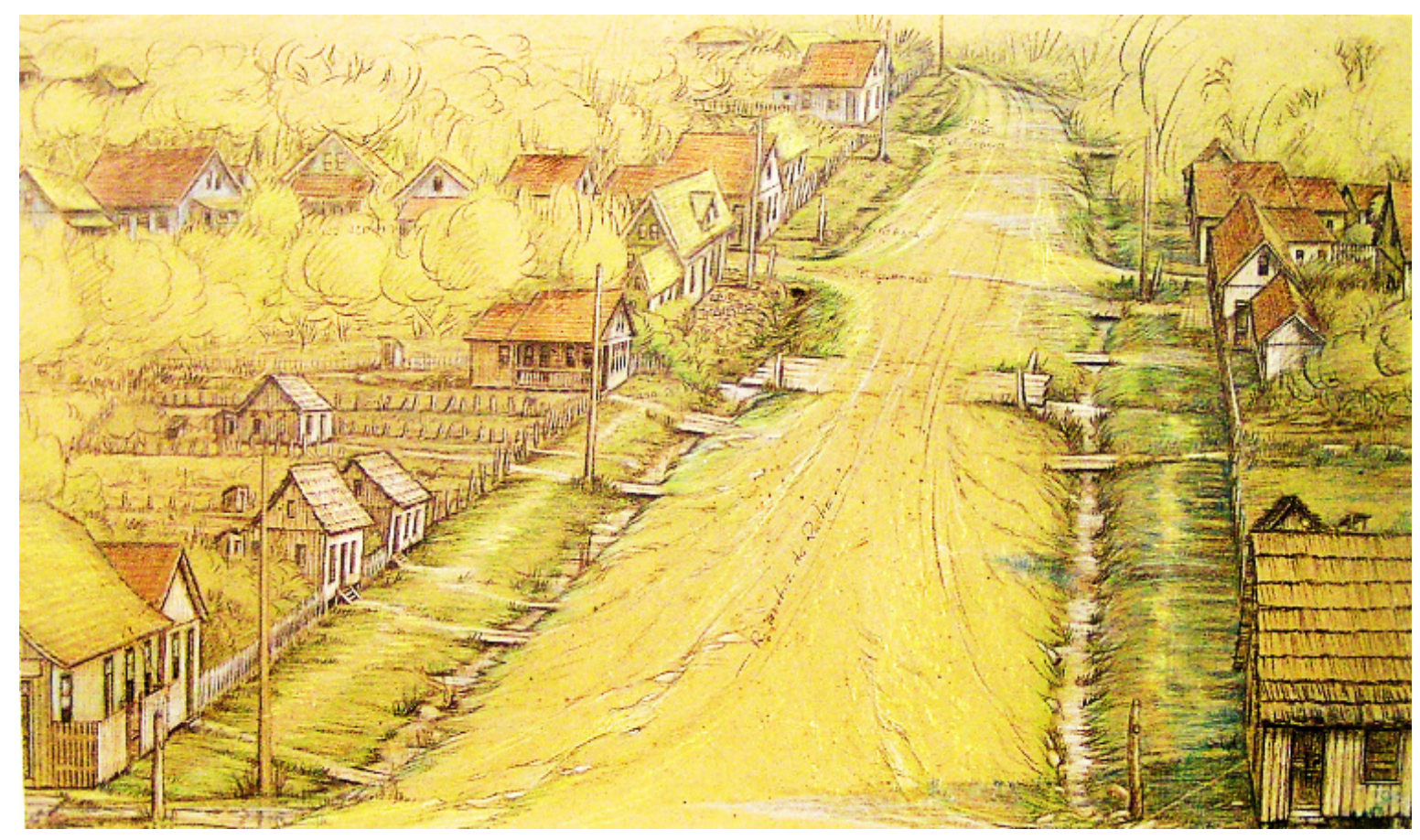

Fonte: Acervo de Zeca Araújo. Fotografia: Ferrari, 2016.

Para a interpretação desta imagem enquanto representação da paisagem estabeleceram-se as seguintes etapas: 1 . Reconhecimento dos elementos visuais que compõe a paisagem retratada; 2. Estabelecimento das possíveis relações existentes entre estes elementos; 3. Obtenção dos significados intrínsecos à imagem da paisagem e de seus elementos. Para esta terceira etapa, que necessita uma base sólida de conhecimento local, contou-se com duas fontes: bibliografia local e entrevistas. A obra de Primo Araújo compôs a fonte principal de dados, as demais possibilitaram a triangulação destes pela combinação de fontes.

O uso da imagem facilitou a interação entre entrevistador/entrevistado permitindo fluidez no processo comunicativo. Para viabilizar uma melhor compreensão da paisagem retratada por Primo Araújo, solicitou-se ao entrevistado que procurasse identificar os elementos nela presentes. Foi possível evidenciar nessa interação relações não visíveis presentes nas obras, através do relato pessoal daquele que teve contato próximo ao artista e que também vivenciou o período da perda paulatina das edificações em madeira em Irati.

Para analisar os elementos remanescentes da paisagem retratada por Primo Araújo foram feitas observações in loco na área central de Irati, mais especificamente na Rua Munhoz da Rocha. Através de caminhadas e utilizando-se de fotografias para o registro, foram detectadas as permanências, mas também as transformações da área.

Partiu-se, portanto, de uma metodologia que permitiu verificar a dinâmica da paisagem em Irati (Geografia) a partir de um de seus elementos, as edificações de madeira (Arquitetura), representadas na obra de Primo Araújo (Arte). 


\section{AS EDIFICAÇÕES EM MADEIRA NA PAISAGEM: RESULTADOS E DISCUSSÕES}

A paisagem da Figura 1 retrata Irati no início do século XX, local que - numa transposição para os dias de hoje - seria, segundo Zeca Araújo (2016), o 'centro nervoso' atual. Neste local situavam-se, ainda segundo Zeca Araújo, as residências das famílias mais abastadas da época, algumas nominadas na legenda, outras anônimas. Um croqui (Fig. 2) permite apontar a esquina da Rua Munhoz da Rocha com Rua XV de Julho na parte inferior da imagem, e com a Rua XV de Novembro na parte superior.

Figura 2: Atual Rua Munhoz da Rocha - croqui elaborado a partir do desenho de Primo Araújo que retrata paisagem de Irati no início do século XX.

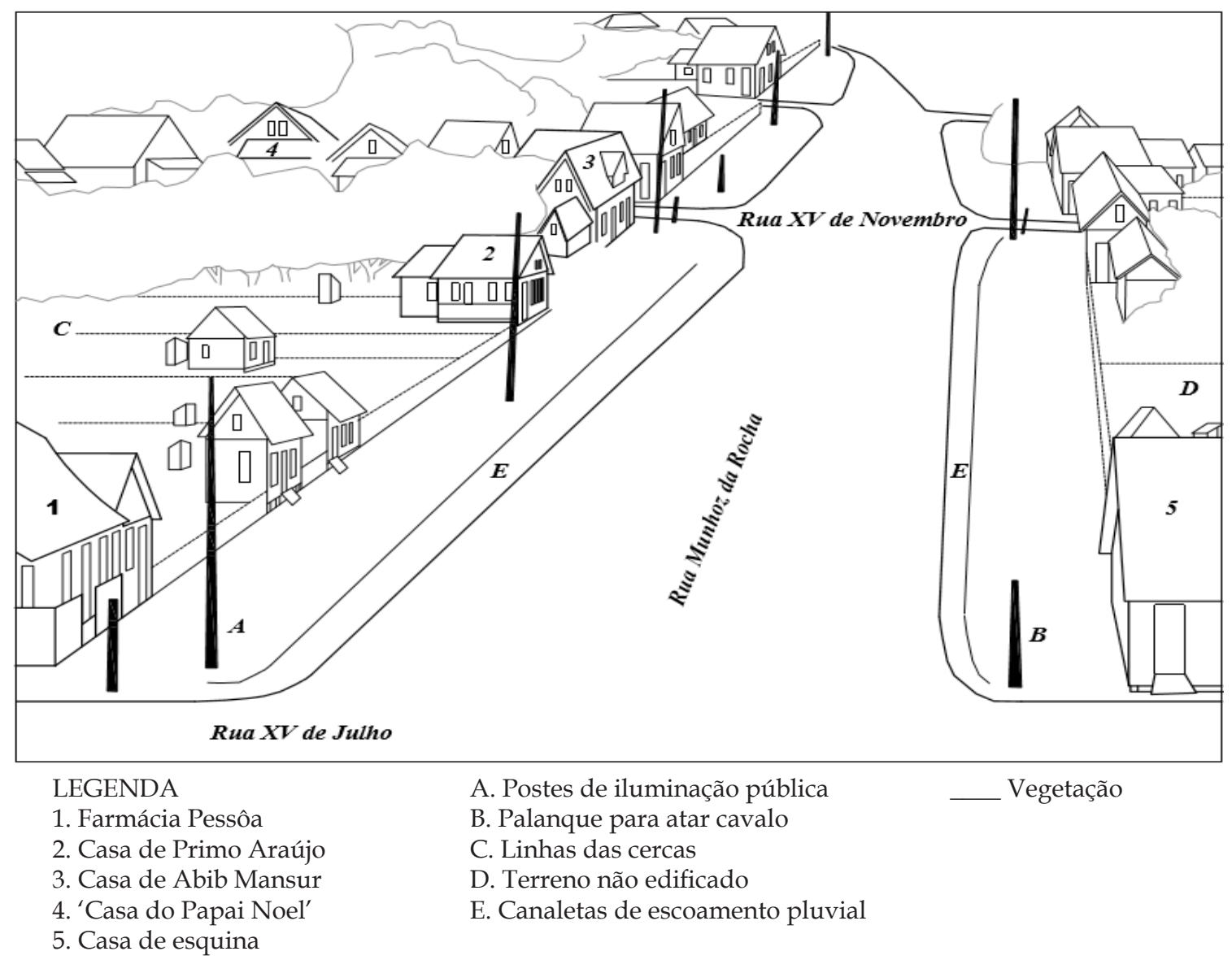

Org.: das autoras.

A partir dos elementos visuais que compõe a paisagem retratada por Primo Araújo, torna-se possível estabelecer as relações que se estabelecem entre eles, bem como, seus significados intrínsecos, conforme disposto na metodologia apresentada. Primeiramente são analisados os elementos contextuais da paisagem, e na sequencia as edificações em madeira, objetos da presente investigação. Por fim, apresentam-se os elementos remanescentes na paisagem retratada por Primo Araújo. 


\section{a) Os elementos contextuais}

Nota-se, na representação da paisagem, que se trata de uma área predominantemente plana, sem grandes desníveis topográficos. O principal elemento natural, representado por Primo Araújo, é a vegetação (Figuras 1 e 2). Os traços que identificam a vegetação não são precisos, portanto, não há clareza quanto à tipologia de espécies vegetais presentes, sendo apenas um recurso figurativo colocado no desenho pelo artista. Trata-se, todavia, de elementos arbóreos de médio porte, que encobrem algumas residências ou parte delas. Não se evidencia a presença da Araucária neste desenho do artista, sendo essa espécie retratada apenas como material construtivo das casas.

Elementos de infraestrutura urbana podem ser identificados na paisagem, destaque para a presença de postes em ambas as margens da estrada (Figuras 1 e 2). Estes informam da presença de luz elétrica nas casas, cuja instalação se deu a partir de 1907, momento em que Manoel Grácia, pai da primeira esposa de Primo Araújo e um dos primeiros comerciantes da cidade, fez um empréstimo de dois contos de reis para viabilizar a aquisição de terra nesta área (ORREDA, 2008).

As marcas ao longo da estrada de terra demonstram a passagem das rodas das carroças que por ela transitavam a época (Fig. 1). O uso da montaria para o transporte também se revela na imagem através de palanques de atar cavalos que aparecem nas esquinas (Figs. 1 e 2). Nas margens esquerda e direita da via estão presentes canaletas escavadas a céu aberto que serviam para escoamento das águas das chuvas, mantendo seco seu leito. Pontilhões feitos de tábuas de madeira cruzam as caneletas permitindo a transposição de pedestres. Os largos passeios em frente às casas, recobertos com grama, apresentam sinais de desgaste nestes locais de fluxo (Fig. 1). De acordo com Orreda (2008), a pavimentação de vias em Irati teve início apenas nos anos 1940 e com ela a infraestrutura associada.

No desenho de Primo Araújo, cercas em madeira delimitam as propriedades, edificadas ou não, separando-as das dos vizinhos e marcando o alinhamento frontal. Ele retrata com bastante riqueza de detalhes cada uma das peças verticais, que posicionadas em linha, servem para demarcar os espaços privados. Na primeira formação do quadro urbano da cidade, no início do século XX, a Câmara distribuiu 'Cartas de Datas ${ }^{5}$ para atribuir a posse dos terrenos a quem tivesse interesse de pagar os impostos (ORREDA, 2008). Assim os lotes que tinham proprietários eram cercados para delimitação destas áreas e posterior ocupação por construções. Em alguns casos, antes que os lotes fossem ocupados e com a autorização dos proprietários, estas áreas eram utilizadas para cultivo de hortas.

\section{b) As edificações em madeira}

As edificações na paisagem de Irati do início do século XX, ainda pouco adensadas, eram feitas de tábuas verticais de madeira, material abundante na região. A madeira 
utilizada, via de regra, era de pinho ou imbuia. Analisa-se na sequencia algumas das características construtivas dessas, bem como, seus significados intrínsecos.

Para evitar o contato da madeira com a umidade do solo, aumentando a durabilidade deste material, era comum que as construções fossem feitas afastadas do chão, soerguidas sobre pilaretes de tijolos cerâmicos ou pedras (Fig. 3-A). Erguer as residências sobre esta base também auxiliava na ventilação do barroteamento ${ }^{6}$ do piso, que também era executado em tábuas de madeira sobre vigas do mesmo material. Esta era uma diretriz arquitetônica comum neste tipo de técnica construtiva, evitando que o material apodrecesse com facilidade em contato com a água e, assim, reduzindo a necessidade de manutenção constante pela troca de peças deterioradas. Com isso, era comum também a presença de pequenas escadas de madeira para o acesso à residência (Fig. 3-B).

Figura 3: Detalhes construtivos das edificações em madeira retratadas no desenho de Primo Araújo.
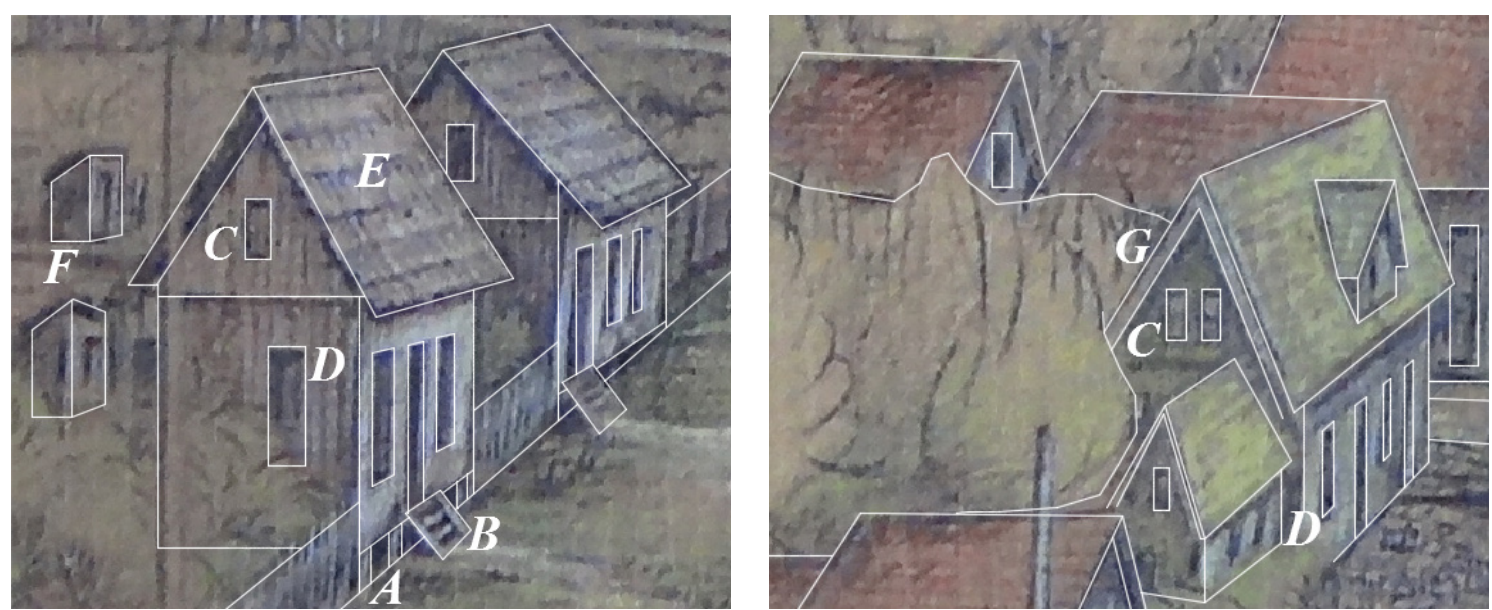

LEGENDA

A. Base da edificação

B. Escada de acesso

C. Sótão
D. Janela em guilhotina

E. Telhado em taubilha

F. 'Casinhas'

G. Adorno de lambrequim

Fonte: Acervo de Zeca Araújo. Org.: das autoras.

Outra característica comum à maior parte das residências retratadas era a existência do sótão (Fig. 3-C), que se faz notar pela presença de janelas para iluminação e ventilação deste na parte superior dos telhados. Em relação à tipologia de esquadrias das janelas, que também eram confeccionadas em madeira, a mais comum era no sistema guilhotina, com duas folhas: uma fixa superior e uma móvel inferior (Fig. 3-D). ${ }^{6}$

Os telhados dessas edificações contavam com dois tipos de materiais, a taubilha ou tabuinha (Fig. 3-E), telha de madeira confeccionada pelos colonos; e as telhas de barro, que eram produzidas em olarias de cidades mais desenvolvidas à época, provavelmente Ponta Grossa, e trazidas para Irati pelos habitantes que tinham melhores condições financeiras. A diferença no material utilizado para a cobertura das edificações, segundo Zeca

$6 \mathrm{O}$ barroteamento é um conjunto de peças (barrotes) de madeira que é apoiado no vigamento e que suporta o contrapiso ou diretamente o piso. 
Araújo (2016), distinguia a classe social de seus proprietários. Algumas residências eram adornadas com lambrequins (Fig. 3-G), adorno de madeira nos beirais também indicando as melhores condições financeiras de seus moradores.

No desenho de Primo Araújo percebe-se a diferença na representação dos materiais das telhas através das cores utilizadas pelo artista. Os telhados de barro destacam-se em tons alaranjados ${ }^{7}$, enquanto os telhados de taubilhas aparecem em tonalidades mais claras. O traço também as diferencia: as taubilhas foram desenhadas com o aspecto mais artesanal próprio do material; as coberturas de barro parecem ter sido ilustradas com traços mais padronizados e regulares.

Afastadas da edificação principal e localizadas na parte posterior dos lotes, as latrinas, chamadas 'casinhas', se faziam presentes na maior parte das propriedades (Fig. 3-F). Trata-se de pequenas estruturas de madeira que abrigavam uma fossa (coberta com um assento vazado) para conter os dejetos humanos, evitando mau cheiro e proliferação de insetos próximos à residência. À época não existiam as instalações sanitárias como se conhece atualmente, nem rede coletora de esgotos domésticos.

Dentre as edificações que aparecem no desenho de Primo Araújo, Zeca Araújo (2016) atribuí características intrínsecas ${ }^{8}$ a cinco delas (Fig. 4).

Figura 4: Edificações de madeira dos primórdios de Irati retratadas pelo artista Primo Araújo.

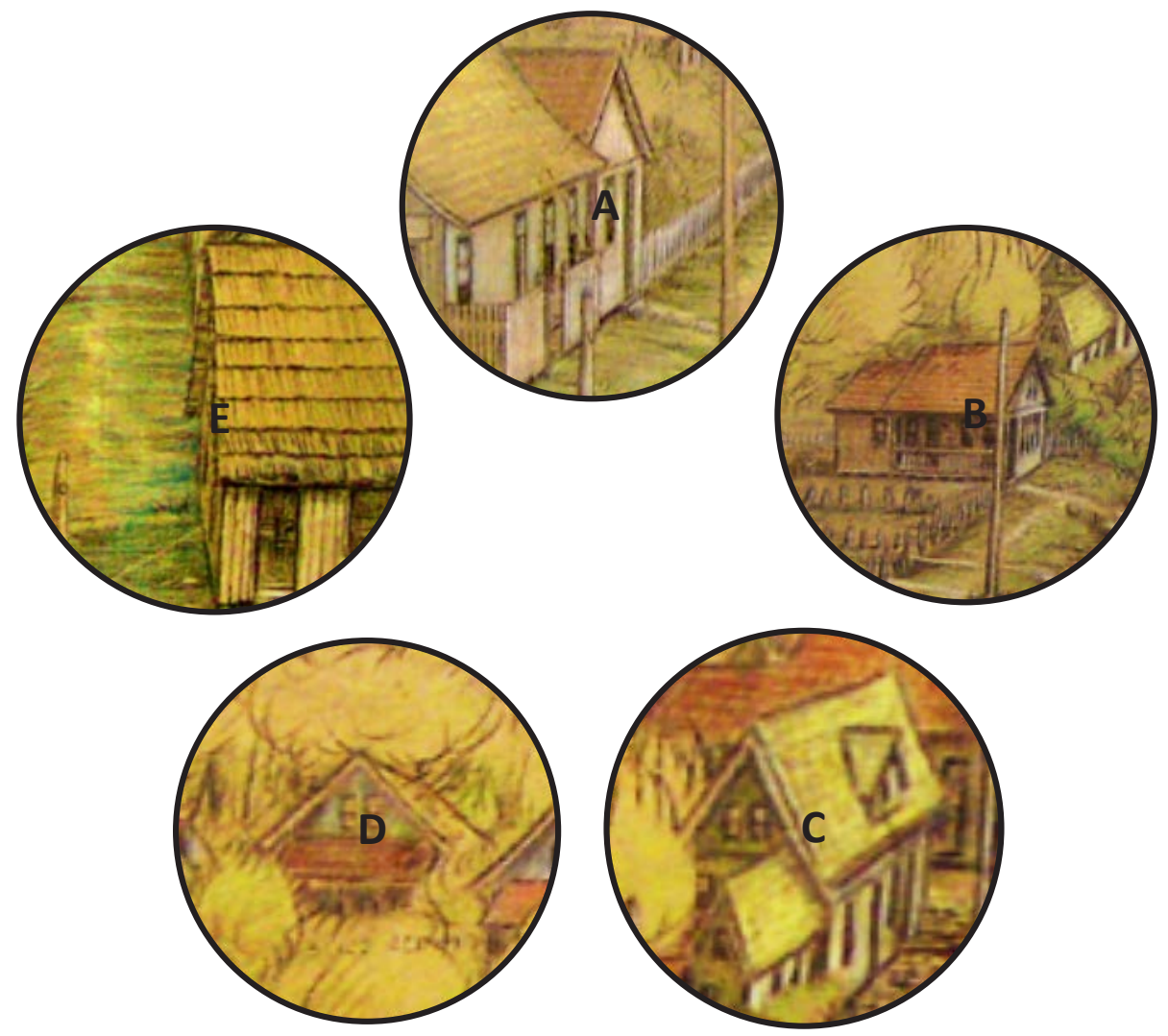

Fonte: Acervo de Zeca Araújo. Org.: das autoras.

7 Algumas residências, as que dão frente à Rua Munhoz da Rocha e que tem as águas do telhado voltadas para o alinhamento da rua são representadas na cor amarela, o que pode sugerir a iluminação natural provocada pela incidência dos raios solares em determinado momento do dia e não necessariamente seu material construtivo.

8 Apenas em três delas, as primeiras, há referência de Zeca Araújo (2016) ao conteúdo social delas no início do século XX. 
A Farmácia Pessôa pertencia ao farmacêutico João de Mattos Pessôa, conhecido por fornecer remédios às pessoas carentes sem cobrar. Ele também se dedicava à atividade madeireira e cerâmica como industrial. Foi prefeito de Irati entre 1946 e 1947 (FARAH; GUIL; PHILIPPI, 2008) e "participou ativamente da construção do Hospital de Caridade São Vicente de Paulo, tornando-se o primeiro provedor" (FARAH; GUIL; PHILIPPI, 2008, p. 40 e 41). A edificação em madeira possuía testadas voltadas tanto para a Rua Munhoz da Rocha, quanto para a Rua XV de Julho (Fig. 4-A). A fachada principal era provavelmente a da Rua XV de Julho, pois nela se percebem os lambrequins adornando o beiral e parte do que supostamente seria a placa de identificação do estabelecimento comercial. Já na fachada voltada para a Rua Munhoz da Rocha vê-se parte da edificação contornada por cercas e com um recuo em relação ao passeio, o que demonstra tratar-se de um acesso secundário.

Há outra edificação muito próxima à construção da esquina, o que pode ser uma propriedade secundária também de posse de João Pessôa. Neste período era comum que os proprietários dos estabelecimentos comerciais residissem ao lado ou, até mesmo, na mesma edificação dedicada ao comércio, entretanto não se identificou o uso e a propriedade desta construção para realizar esta afirmação.

A casa de Primo Araújo (Fig. 4-B) era marcada por uma ampla fachada frontal, na qual se percebem quatro janelas no térreo e outras duas no oitão da cobertura. Na lateral esquerda vê-se uma ampla varanda voltada para o quintal e protegida por um guarda corpo. A parte mais baixa, localizada aos fundos da edificação principal era provavelmente a cozinha da residência. Na parte posterior do terreno, um pouco afastada da casa, está a latrina. Cercas demarcam precisamente o lote pertencente à família. Nesta casa, segundo Araújo (2016), nasceram os cinco filhos do artista.

A residência localizada na esquina das ruas Munhoz da Rocha e XV de Novembro pertencia a Abib Mansur e sua esposa Nazle Kfouri Mansur (ARAÚJO, 2016). Ambos nasceram no Líbano e chegaram a Irati no início do século XX. Abib administrava vários negócios no município: um armazém de cereais e serrarias, além de uma estância de água mineral em Pirapó. Dos seis filhos do casal, João Mansur, foi o mais conhecido por sua carreira como vereador e por ter sido eleito prefeito da cidade em 1955 (FARAH; GUIL; PHILIPPI, 2008), além de governador do Paraná.

A casa de Abib Mansur era ampla e ocupava boa parte da esquina, numa distribuição espacial que na imagem (Fig. 4-C) parece ser em ' $L$ ', com testadas voltadas tanto para a Rua Munhoz da Rocha quanto para Rua XV de Novembro. Na água da cobertura voltada para a Rua Munhoz da Rocha percebe-se a mansarda no telhado - esta janela auxiliava na iluminação e ventilação do sótão. Também existe ao lado esquerdo do volume principal da construção, uma área edificada mais baixa que poderia ter sido a cozinha.

Localizada na Rua XV de Novembro, outra residência chama atenção no desenho, não por seu destaque na obra, mas por ser a única edificação remanescente desta paisagem. Zeca Araújo (2016) não se lembra exatamente de quem era esta propriedade, apenas citou a mesma como 'Casa do Papai Noel', por ela ter sido utilizada em período mais contemporâneo para atividades natalinas (Fig. 4-D). Zeca conta ainda que o Cine Theatro Central se localizava ao lado dessa casa, porém este foi inaugurado apenas em 28 de agosto de 
1920 (ALMEIDA, 2013). A residência de duas águas possui uma varanda frontal coberta e duas janelas que iluminam o sótão no oitão da fachada principal. Nota-se ainda, como elemento do desenho, os lambrequins que dão acabamento ao beiral.

A última residência, destacada por Zeca Araújo (2016), é a casa da direita no cruzamento entre as ruas Munhoz da Rocha e XV de Julho (Fig. 4-E). Não há menção sobre quem foi seu proprietário. Na ilustração é visível a construção da casa sobre uma base que a distância do solo, a pequena escadaria que dá acesso à porta e o telhado inclinado provavelmente feito com taubilhas. É possível observar que a porta possui almofadas, relevo realizado nas esquadrias para decorar e dar maior destaque a estes elementos.

Destas edificações em madeira retratadas por Primo Araújo, apenas a 'Casa do Papai Noel' ainda está presente na paisagem central de Irati. Esta e outras reminiscências são apresentadas na sequencia.

\section{c) Os elementos remanescentes}

Buscando verificar a permanência de elementos da paisagem de Irati no início do século XX retratada por Primo Araújo, foram realizadas observações in loco. Comparando este eixo retratado pelo artista com a situação atual da Rua Munhoz da Rocha (Fig. 5), no trecho entre as ruas XV de Novembro e a XV de Julho, foi possível identificar duas permanências: o traçado das ruas e uma edificação em madeira.

Figura 5: Registro fotográfico da paisagem atual da Rua Munhoz da Rocha.

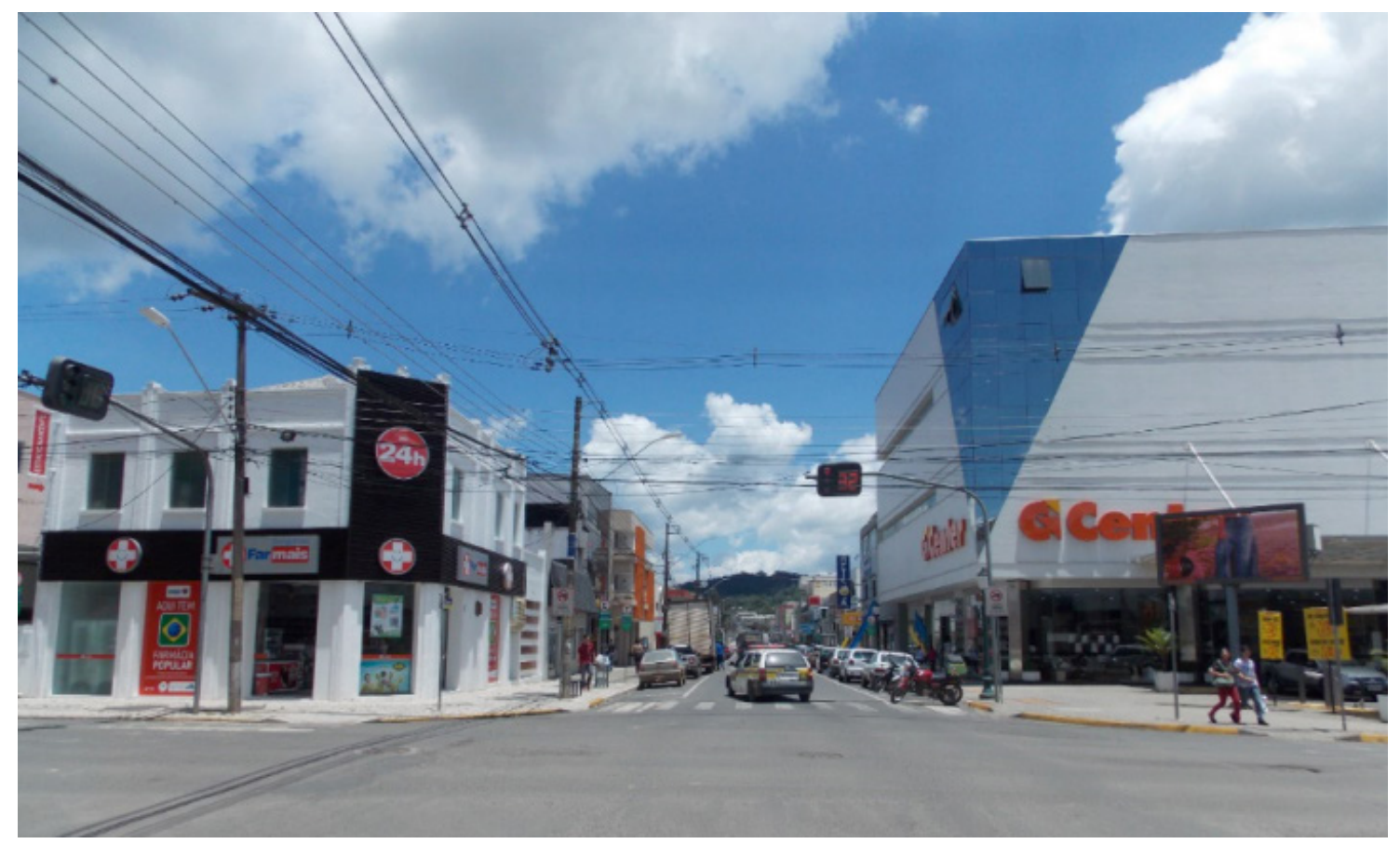

Fonte: Ferrari, 2016

A esquina onde se localizava a Farmácia Pessôa, hoje abriga outra edificação erigida em dois pavimentos, todavia com a mesma função. No lugar da casa de madeira com 
cobertura de taubilhas localizada em frente, na esquina oposta, tem-se hoje um estabelecimento comercial de três pavimentos (G. Center). A antiga casa de Primo Araújo já não existe mais na paisagem, no seu lugar há uma edificação de alvenaria de dois pavimentos, que abriga a Regional de Saúde. O casarão de Abib Mansur tampouco permaneceu na paisagem.

A estrada retratada pelo artista, todavia, mantem o seu traçado e o posteamento de rede elétrica no seu lado esquerdo. A antiga estrada de terra é atualmente uma via pavimentada em asfalto, com faixas de estacionamento em ambos os lados. O ocasional tráfego de carroças deu lugar ao grande movimento de veículos, disciplinado por semáforos. Não existem mais os espaços abertos vegetados do passado.

A paisagem é hoje muito mais adensada, com edifícios de até três pavimentos e uso comercial no térreo. Há um excesso de elementos de comunicação visual, como fachadas coloridas, letreiros com o nome dos estabelecimentos e placas de trânsito. Percebe-se também a presença de mobiliário urbano, como lixeiras e bancos, substituindo os antigos palanques de atar cavalos. No lugar das antigas canaletas escavadas para escoamento pluvial há hoje galerias pluviais encobertas pelas sarjetas.

Os edifícios novos, com diversos pavimentos, encobrem o horizonte, ficando visível apenas uma pequena elevação aos fundos da via. Uma edificação de madeira retratada por Primo Araújo, entretanto, permanece na paisagem. Trata-se da denominada 'Casa do Papai Noel' (Fig. 4-D), reconhecida por este nome por ter servido à visitação pública e decorada especialmente para as festividades de Natal, atraindo visitantes e especialmente crianças há alguns anos atrás. Esta, todavia, encontra-se fechada e parcialmente escondida pela vegetação urbana, não havendo sinais de ocupação recente. Um muro com base de alvenaria e gradil metálico demarca o lote na atualidade (Fig. 6), com o jardim florido de aspecto agradável. A casa com pintura branca contrasta com esquadrias em verde. Na maioria das janelas mantem-se o sistema guilhotina e na varanda o diferencial são as folhas de vidro das janelas com abertura para o lado externo e as folhas de madeira voltadas para o interior. A base vazada feita de tijolos para isolar a madeira da umidade do chão, dando maior durabilidade ao material, também foi pintada de verde, assim como os lambrequins que adornam os beirais.

A varanda coberta na parte frontal dá acesso à porta principal, também em madeira com almofadas. $\mathrm{O}$ formato retangular da edificação demonstra uma planta simplificada distribuindo os cômodos. No frontão duas janelas iluminam o sótão. A cobertura é feita por telhas de barro planas. 
Figura 6: 'Casa do Papai Noel' - registro fotográfico atual da edificação em madeira remanescente na Rua Munhoz da Rocha.

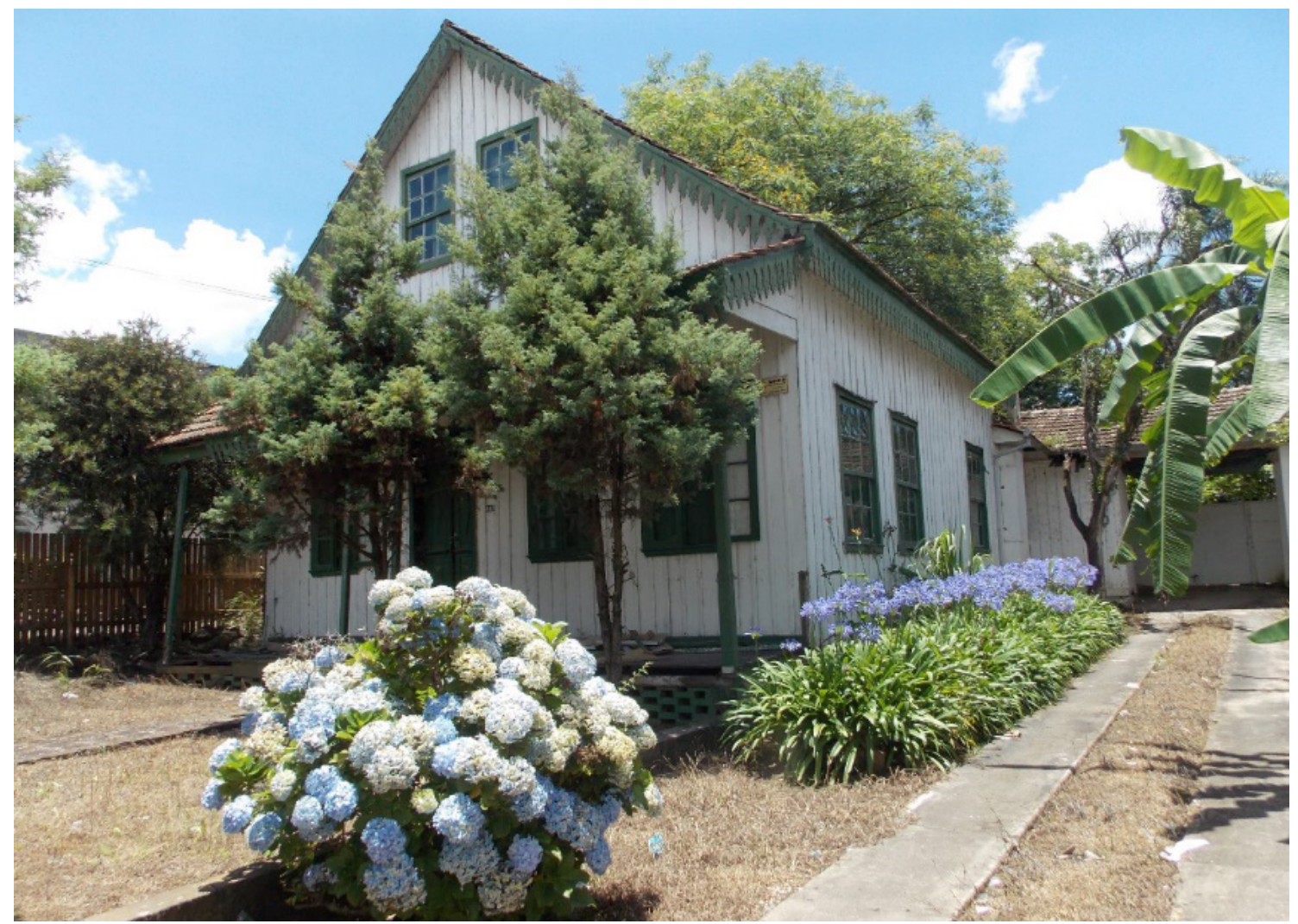

Fonte: Ferrari, 2016.

\section{CONSIDERAÇÕES FINAIS}

O avanço da ocupação humana e a necessidade de adaptações em relação às dinâmicas culturais e econômicas se refletem, de um lado, na ocupação do solo urbano e na organização sócio espacial da cidade. A interpretação da paisagem do passado com os instrumentos atualmente disponíveis, de outro lado, provocam mudanças na forma subjetiva de interpretá-la e levam também à resignificação desta.

Ressalta-se, desta forma, a relevância das obras de arte e das paisagens nelas retratadas, que permitem resgatar as tradições que foram deixadas para trás, as estruturações sócio espaciais do passado, enfim, a história e geografia local. As obras de Primo Araújo permitem a aproximação de paisagens do passado num contexto específico, o da cidade de Irati. $\mathrm{O}$ desenho selecionado em seu acervo possibilita avaliar a presença massiva de edificações de madeira enquanto elementos da paisagem iratiense no início do século XX, bem como outros elementos contextualizadores, como a presença de rede elétrica e do transporte de carroça naquele momento histórico.

Primo Araújo realizou este desenho numa época na qual grande parte das edificações em madeira já havia sido substituída por construções em alvenaria. A partir das décadas de 1930 e 1940 Irati passa por grandes transformações urbanas, incluindo a substituição do método construtivo em madeira. Muitas olarias se desenvolveram na região neste 
período, o que acabou promovendo a utilização de tijolos e telhas cerâmicas e, com isso, a diminuição do uso da madeira.

Portanto, o próprio artista reconstrói, através do desenho, uma paisagem do passado. Esta imagem indica uma visão saudosista, que possivelmente pode ser interpretada como a falta que Primo Araújo sentia dos elementos urbanos que já não se encontravam na paisagem da cidade, especialmente as edificações em madeira. Assim, através dos seus desenhos, o artista resgata estes elementos e através destes registros promove a preservação da identidade local.

O desenho analisado demonstra o desejo do artista em deixar apontada em obras de arte a organização espacial específica de um tempo, a história do município, e ainda em resgatar a memória de um tempo do qual fez parte, um contexto que ele mesmo vivenciou na juventude. Por detalhar mais precisamente as edificações neste desenho, o artista mostra ser um admirador da arquitetura tradicional em madeira. Esta indicação se dá também pela percepção de que na imagem não estão detalhadas outras informações: a vegetação aparece de forma indicativa e não se destacam figuras humanas.

Uma comparação entre a paisagem retratada pelo artista com a paisagem atual fotografada revelou algumas permanencias e muitas transformações ocorridas neste espaço no periodo de um século. Entre as permanencias, além do traçado urbano mantido, detectou-se a reminicência de uma única edificação de madeira. A edificação, conhecida como "Casa do Papai Noel”, apresenta-se como uma patrimônio arquitetônico emblemático, que merece maior atenção tanto por parte da população iratiense, como também, do poder público.

A sistematização do acervo de Primo Araújo vem sendo realizada com dedicação por Zeca Araújo, filho do artista, todavia, urge a necessidade de apoio a esse trabalho, bem como a maior profissionalização deste. O conjunto desta obra permite viabilizar não apenas o resgate da contribuição do artista local, mas também da memória das paisagens nela representada.

As interfaces existentes entre a Geografia, a Arquitetura e a Arte, contribuíram aqui para este desvendar da paisagem urbana de Irati. A contribuição da Geografia deuse através do conceito de paisagem numa postura integradora entre elementos físicos e humanos. A Arquitetura permitiu a interpretação das edificações em madeira enquanto elementos visíveis da paisagem, mas também de seus aspectos ocultos, como é o caso das relações sociais. Já a Arte, concretizada na obra do artista local Primo Araújo, possibilitou a articulação entre as perspectivas dessas diferentes áreas.

\section{REFERÊNCIAS}

ALMEIDA, Pedro Henrique Wasilewski. A História do Cine Theatro Central de Irati. Documentário, 2013. Disponível em: https:/ / www.youtube.com/watch?v=bJTFbDQs7F4. Acesso em: 27 jul. 2016. .

ANDREOTTI, Giuliana. Paisagens Culturais. Curitiba: Ed. UFPR, 2013. 
ANGOTTI-SALGUEIRO, Heliana. A construção de representações nacionais: os desenhos de Percy Lau na Revista Brasileira de Geografia e outras "visões iconográficas" do Brasil moderno. Anais do Museu Paulista, São Paulo, v.13, n.2, p.21-72, jul./dez. 2005.

ARAÚJO, José Maria Grácia. In: RADIO NAJUÁ. Irati de Todos Nós. Homenagem aos pais. 2010. Disponível em: <http://m.radionajua.com.br/noticia/irati-de-todos-nos/materias/homenagem-aos-pais/4576/>. Acesso em: 06 jun. 2016.

ARGAN, Giulio Carlo. História da arte como história da cidade. 6 ed. São Paulo: Martins Fontes, 2014.

BARDIN, Laurence. Análise de conteúdo. Lisboa: Edições 70, 1977.

BERQUE, Augustin. Paisagem-marca, Paisagem-matriz: elementos da problemática para uma Geografia Cultural. In: CORREA, Roberto Lobato; ROSENDAHL, Zeny (Orgs.). Paisagem, tempo e cultura. 2 ed. Rio de Janeiro: Ed. UERJ, 2004. p.84-91.

CARVALHO, Paulo Ernani Ramalho; MEDRADO, Moacir José Sales; HOEFLICH, Vitor Afonso. Cultivo do pinheiro-do-paraná. Colombo: Embrapa Florestas, 2003. (Sistemas de Produção, 7).

COLASANTE, Tatiana; CALVENTE, Maria del Carmen Matilde Huertas. A abordagem do conceito de patrimônio cultural em artigos científicos da área de Geografia (2005 - 2011). In: ENCONTRO NACIONAL DE GEÓGRAFOS, 17, 2012, Belo Horizonte. Anais... p. 9.

CORRÊA, Roberto Lobato. Denis Cosgrove: a paisagem e as imagens. Espaço e Cultura, n. 29, p.7-21, jan./ jun. 2011.

DEMCZUK, Paula Grechinski. Ferrovia e turismo: reflexões sobre o Patrimônio Cultural Ferroviário em Irati (PR). 2011. Dissertação (Mestrado em Geografia), Universidade Estadual de Ponta Grossa, PR.

FARAH, Audrey Lilian Souza; GUIL, Chico; PHILLIPI, Silvio José. Irati 100 anos. Curitiba: Arte, 2008.

FERREIRA, Lohanne Fernanda Gonçalves. Geografia e arte: uma análise da produção da representação da favela nas obras de Cândido Portinari. Terr@Plural, v.11, n.2, p.304-326, jul./dez. 2017. Disponível em: <http://www.revistas2.uepg.br/index.php/tp/article/view/10515/pdf>. Acesso em: 26 fev. 2018.

GOMES, Paulo Cesar da Costa; RIBEIRO, Leticia Parente. A produção de imagens para a pesquisa em geografia. Espaço e Cultura, n.33, p.27-42, jan./jun. 2013. Disponível em: <http:/ / www.e-publicacoes.uerj. br/index.php/espacoecultura/article/view/8465/6275>. Acesso em: 13 mar. 2018.

KIEWIET, Ruth; KIEWIET, Willem. Imigrantes Immigranten: história da imigração holandesa na região dos Campos Gerais, 1911-2011. A Colônia de Gonçalves Júnior - Irati - PR: A imigração holandesa de 19081909 no Brasil. Carambeí: Estúdio Texto/ APHC Editorial/NMC - Núcleo de Mídia e Conhecimento, 2011.

MARQUEZ, Renata Moreira. Arte e geografia. In: FREIRE-MEDEIROS, Bianca; COSTA, Maria Helena Braga e Vaz da (Orgs.). Imagens Marginais. Natal: Ed. UFRN, 2006, p.11-22.

NOVAES, André Reyes. Geografia e História da Arte: apontamentos para uma crítica à icnologia. Espaço e Cultura, n.33, p.43-64, jan./jun. 2013. Disponível em: <http://www.e-publicacoes.uerj.br/index.php/ espacoecultura/article/view/8466>. Acesso em: 13 mar. 2018.

ORREDA, José Maria. Irati, teu nome é economia. Revista do Centenário 1907-2007: Cem Anos de História. Irati: O Debate, 2008. v.7.

SILVA, Andressa Henning; FOSSÁ, Maria Ivete Trevisan. Análise de conteúdo: exemplo de aplicação da técnica para análise de dados qualitativos. Qualit@s Revista Eletrônica, v.17, n.1, p.1-14, 2015. Disponível em: <http:// revista.uepb.edu.br/index.php/qualitas/article/view/2113/1403>. Acesso em: 15 mar. 2018.

SOUZA, Marcelo Lopes de. Os conceitos fundamentais da pesquisa sócio-espacial. Rio de Janeiro: Bertrand Brasil, 2013.

ZEVI, Bruno. Saber ver a arquitetura. 5 ed. São Paulo: Martins Fontes, 1996.

Data de submissão: 28/jan./2018

Data de aceite: 13/maio/2018 